\title{
Zirconium Determination by Cooling Curve Analysis during the Pyroprocessing of Used Nuclear Fuel
}

\author{
B.R. Westphal ${ }^{1 *}$, J.C. Price ${ }^{1}$, K.J. Bateman ${ }^{1}$, and K.C. Marsden ${ }^{1}$ \\ ${ }^{1}$ Idaho National Laboratory, P.O. Box 1625, Idaho Falls, ID 83415 \\ ${ }^{*}$ Corresponding author. Tel.: 208533 7398; fax: 2085337471. \\ E-mail address: brian.westphal@inl.gov (B. Westphal).
}

\begin{abstract}
An alternative method to sampling and chemical analyses has been developed to monitor the concentration of zirconium in real-time during the casting of uranium products from the pyroprocessing of used nuclear fuel. The method utilizes the solidification characteristics of the uranium products to determine zirconium levels based on standard cooling curve analyses and established binary phase diagram data. Numerous uranium products have been analyzed for their zirconium content and compared against measured zirconium data. From this data, the following equation was derived for the zirconium content of uranium products:

$$
\mathrm{Zr}=0.14 \mathrm{M}+131.56-12.63(348.65-0.16 \mathrm{LT})^{1 / 2}
$$

where $M$ is the mass $(\mathrm{kg})$ of the ingot and $L T$ is the liquidus temperature $(K)$ found by cooling curve analyses. Based on this equation, a reasonable fit of calculated to measured zirconium content was established considering the errors in the system.
\end{abstract}

\section{Introduction}

During the pyrometallurgical treatment of used Experimental Breeder Reactor-II (EBR-II) fuels, a casting step was incorporated to originally cast metal fuel into elemental form for continued irradiation of the fuel in a fast reactor [1-2]. More recently, the casting step has been utilized for down-blending of uranium products to low enriched uranium (LEU) and sampling purposes [3]. Sampling of the uranium products involves injecting molten metal into quartz molds and solidifying the metal so that representative samples can be sectioned and analyzed by dissolution chemistry. Since the uranium products are slightly radioactive [4], the casting and chemical analyses are performed in shielded facilities with remote handling capabilities.

A viable alternative to the labor intensive sampling and analysis program is to monitor the melt in real-time for impurity content by cooling curve analysis (CCA) which is common practice in the steel industry [5]. Since phase equilibria have been established for countless systems, monitoring the cooling curve of a simple binary system is straightforward in that correlation with a liquidus curve is feasible. For the uranium products from the pyroprocess, the impurity with the greatest concentration is zirconium. Zirconium derives from the original fuel as an alloying agent with uranium and can be carried along electrochemically due to its similarity with uranium [6-7]. Thus, the zirconium content of the uranium products can be determined by analyzing the casting cooling curves and comparing against the $U-Z r$ phase diagram for compositional data.

The purpose of this paper is to describe the casting equipment and operation using representative cooling curve data such that the zirconium content of the uranium products can be determined. The zirconium content found by conventional chemical analyses will be contrasted against that found from cooling curve analysis. Due to the inherent characteristics of the casting system, an offset exists between the measured and calculated zirconium levels. 
This offset will be addressed and quantified. Also, a brief discussion on the liquidus portion of the U-Zr phase diagram will also be included to establish a basis for liquidus temperatures.

\section{Experimental}

The development of metallic fuel casting by injection into quartz molds was initiated for the original EBR-II fuel cycle in the 1960s [2, 8]. Based on the success of this method and the integrity of the fuel for reactor operations, several different casting furnaces have been utilized for the production of metallic fuel for EBR-II including the current unit producing uranium products from the pyroprocess. The current unit is located in a hot cell environment where all operations are performed remotely with electro-mechanical manipulators. More than 100 heats of the current casting furnace have been performed to down-blend, sample, and produce uranium products ranging in size from $15-50 \mathrm{~kg}$. The uranium products, following characterization by chemical analyses, are placed in interim storage awaiting final disposition.

Shown in Figure 1 is a schematic of the inductively-heated casting furnace utilized for the melting and casting of uranium products. The furnace is capable of temperatures as high as $1873 \mathrm{~K}$ and vacuum to less than $1333 \mathrm{~Pa}$ (10 Torr). The vacuum capability is instrumental in casting molten metal into the quartz molds. Following a system evacuation, the molds are submerged into the melt and the system is repressurized rapidly to fill the molds. A graphite crucible coated with yttria contains the melt and two thermocouples (type $\mathrm{C}$ ), located under the crucible, to monitor the crucible temperature during the casting process. The temperature measurements from the thermocouples are recorded by a data archival system. An immersion thermocouple was also designed into the equipment to monitor the temperature of the molten alloy during the casting process but has only been used sporadically. Although feasible, its use for cooling curve analysis would require either consumable components or reheat of the solidified ingot for hardware removal.

A typical operation of the casting furnace includes loading the crucible with a previously consolidated ingot from cathode processing, heating the furnace above the melting point of the alloy (superheat), casting the molten alloy, removing the quartz molds from the melt, and allowing the furnace to cool passively. Superheat is required to compensate for heat losses incurred during the submersion of the molds into the melt and assures a molten mass is available for casting. Water cooling of the casting furnace is not an option due to criticality concerns in the argon atmosphere of the shielded hot cell. Following a casting, the cast pins are removed from the quartz molds, sectioned, and sent to the analytical laboratory for chemical analyses. In the laboratory, the sections are dissolved in nitric acid and analyzed by inductivelycoupled plasma atomic emission spectroscopy (ICP-AES) techniques. A Prodigy (Teledyne Leeman Labs, Hudson, NY) instrument was utilized for ICP-AES. The ICP-AES has been modified for use with radioactive samples to limit personnel exposure by operation of the plasma in a shielded glovebox and monitoring of the transmission by a spectrometer located exterior to the box.

\section{Cooling Curve Analyses}

Depicted in Figure 2 is a typical time-temperature plot for the casting operation as taken from the thermocouples located underneath the crucible. The mass of this uranium product was 18.2 $\mathrm{kg}$ and the measured zirconium content was $0.39 \mathrm{~mol} \%$. Fluctuations in the maximum temperature are induced by cycling of the power input to the furnace to assure stirring of the molten metal. Inflections are visible on the cooling portion of the plot indicating phase changes. Point 1 represents the liquidus temperature of the alloy and points 2 and 3 represent allotropic phase transitions of uranium. The inflections are due to the evolution of latent heat during the 
phase transitions causing the normal cooling rate of the alloy to be affected. It is interesting to note that the inflections are clearly evident despite the use of thermocouples external to the crucible.

The exact point of inflection on a cooling curve is determined by taking a first derivative of the time-temperature data [5]. For the data provided in Figure 2, a plot of the first derivative (dT/dt) versus temperature is shown in Figure 3. Point $A$ on Figure 3 depicts the first inflection (Point 1 on Figure 2) on the cooling curve at approximately $1473 \mathrm{~K}$ and represents the liquidus temperature of the melt.

Traditional cooling curve analyses are performed utilizing internal measurements taken either in the center of the melt or at the wall in order to observe the solidification characteristics. It is also for this reason that thermal analyses using calorimetry are performed with thermocouples in contact with the molten material of interest. Induced by these measurements is a discrepancy from the true equilibrium or liquidus temperature caused by the cooling rate of the melt $[5,9]$. The discrepancies are small for calorimetry considering the sample sizes but may be significant for larger masses. Thus, although in situ temperature measurements are the accepted practice, it should be realized that their measurements have limitations, particularly for larger systems.

Since solidification of the metal occurs from the exterior of the melt to the center, thermocouples located near the wall, both interior and exterior to the melt, record data during solidification that are comparable but differ by the thermal characteristics of the crucible. By balancing heat transfer between a molten metal and a mold, Chvorinov derived a rule that correlates solidification time directly to a modulus factor [10]. The modulus factor is simply the volume to surface area ratio of a casting as shown in the following equation:

$$
t=C(V / A)^{2}
$$

where $t$ is solidification time, $\mathrm{C}$ is a constant based on melt and mold properties, $\mathrm{V}$ is volume, and $A$ is the surface area. Applying Chvorinov's rule to the casting of uranium products, the mass or volume to surface area ratio of uranium will have an effect on the heat transfer properties of the melt and thus, the cooling curve analyses.

The effect of mass on the cooling rate of the melt during the solidification of uranium products is shown in Figure 4. The cooling rate of the ingots was taken from time-temperature data during the first 30 minutes following the termination of power to the furnace. The cooling rate decreases from a high of about $15 \mathrm{~K} / \mathrm{min}$ for a $15 \mathrm{~kg}$ ingot to approximately $10 \mathrm{~K} / \mathrm{min}$ for a $50 \mathrm{~kg}$ ingot which corresponds to Chvorinov's rule; the greater the ingot mass or volume, the longer the solidification time.

\section{U-Zr Phase Diagram}

Despite numerous investigations of the $U$-Zr phase diagram [11-15], the liquidus region is not as well defined as other portions of the diagram. In fact, deficiencies in experimental liquidus data have been acknowledged as well as difficulties with a calculated liquidus based on thermochemical data [12,14-15]. It is for this reason that only experimental data are considered such that a liquidus curve can be established based on the data from several different investigators. Shown in Figure 5 is the liquidus curve of the $\mathrm{U}-\mathrm{Zr}$ phase diagram which includes both experimental data as well as established melting point data for uranium $(1408 \mathrm{~K})$ and zirconium $(2128 \mathrm{~K})$ [16]. A polynomial fit of the data yields the following equation which allows the determination of the liquidus temperature for any given $\mathrm{Zr}$ concentration:

$$
L T=-0.0396(Z r)^{2}+11.208(Z r)+1408
$$


where $\mathrm{LT}$ is liquidus temperature $(\mathrm{K})$ and $\mathrm{Zr}$ is zirconium content (mol \%).

\section{Results}

Shown in Table 1 are the liquidus temperatures obtained by cooling curve analyses for numerous uranium products. Using equation (2), a value, in mol \%, for zirconium content can be calculated and is compared to the zirconium content measured by chemical analyses. The difference between the calculated and measured zirconium is shown in the last column of Table 1. By plotting the delta between the two zirconium values against the mass of the uranium product ingots (Figure 6), a similar trend to cooling rate in Figure 4 is recognized. The variability of the data in Figures 4 and 6 differs due to the limit of error (1\%) on a type $C$ thermocouple especially relative to time. The data in Table 1 and Figure 6 encompass more than 10 years of measurements which includes several thermocouple replacement operations. In contrast, the data in Figure 4 incorporates two thermocouple measurements for each data point 30 minutes apart. Not only does ingot size have an effect on the thermal characteristics of solidification, but obviously also the difference between the values of zirconium.

Regressing the data in Figure 6 linearly results in the following equation:

$$
\Delta \mathrm{Zr}=-0.14 \mathrm{M}+9.95
$$

where $\Delta \mathrm{Zr}$ is the difference between the zirconium content (mol \%) calculated from CCA and the measured zirconium content ( $\mathrm{mol} \%)$, and $\mathrm{M}$ is the ingot mass $(\mathrm{kg})$ quantified following a casting operation. By combining equations (2) and (3), a relationship can be derived that allows for the determination of $\mathrm{Zr}$ content based on the liquidus temperature (LT) found by CCA and the ingot mass $(\mathrm{M})$. This relationship is shown in the following equation:

$$
\mathrm{Zr}=0.14 \mathrm{M}+131.56-12.63(348.65-0.16 \mathrm{LT})^{1 / 2}
$$

\section{Discussion}

As evident in Figure 6, a physical characteristic of $\mathrm{U}-\mathrm{Zr}$ alloys that has been noted historically is the tendency of zirconium to segregate to external surfaces upon cooling due to density differences. This is the primary reason homogeneous molten samples are taken for chemical analyses at the casting furnace [8]. Based on the data in Figures 4 and 6, smaller ingots cool faster, causing more segregation of zirconium while larger ingots cool slower, resulting in less segregation. Thus, the zirconium values determined by CCA are in all cases greater than those measured from chemical analyses of the pin samples as confirmed by the data in Table 1. For the limited runs performed with the immersion thermocouples, it was also recognized that the external thermocouple temperatures were higher than those temperatures read by the internal or immersed thermocouples. Hence, the segregation of zirconium as well as ingot size have an effect on the cooling characteristics of the uranium products.

A comparison of the zirconium measured by chemical analyses and the calculated zirconium using equation (4) is shown in Figure 7. The solid line in Figure 7 represents a perfect fit of the calculated and measured zirconium data. The standard deviation on the calculated to measured data approaches $30 \%$. As can be seen, the data resides both above and below the line indicating data not systematically biased by either analytical measurements, cooling curve analyses, or zirconium segregation. If zirconium segregation were the sole source of bias, the data would consistently lie on one side of the solid line. Possible sources of error include the $+/-$ $5 \%$ error at two sigma on the measured analytical data for ICP-AES and sampling errors both in 
the analytical laboratory as well as following casting. The largest recognized error in the calculated zirconium data derives from the type $\mathrm{C}$ thermocouple measurements. When extrapolated, the $1 \%$ error equates to $12 \mathrm{~K}$ at $1473 \mathrm{~K}$ which translate to between $10-20 \%$ for the calculated zirconium values. Other minor errors in the calculated zirconium data include balance errors when measuring ingot mass, interpretation errors associated with cooling curve analyses due to limitations in the frequency of data collection, and inherent deviations or random errors in the original temperature data. Given these errors, the calculated zirconium values in Figure 7 relate reasonably well to those found via analytical measurements.

The primary advantage to the determination of zirconium content from cooling curve analyses is the elimination of sampling and chemical analyses operations which, considering the irradiated nature of the materials, are significant in terms of time and cost. As shown by the comparison of measured and calculated data in Figure 7, deviations are recognized and can be attributed to zirconium segregation, thermocouples errors, and to a lesser extent other errors. Improvements to the fit of data in Figure 7 would be realized by using more accurate thermocouples, such as type $\mathrm{R}$ or $\mathrm{S}$, under a periodic calibration cycle to minimize the uncertainties in the temperature measurements. With an improvement in the limit of error from $1 \%$ to $0.25 \%$, type $\mathrm{R}$ and $\mathrm{S}$ thermocouples would reduce the standard deviation on the calculated zirconium values significantly from those with the type $\mathrm{C}$ thermocouples used in this study.

\section{Conclusions}

A method for the determination of zirconium content in real-time of uranium products from the pyroprocessing of EBR-II used nuclear fuel has been established. The method relies on the analyses of cooling curves and the $U$-Zr phase diagram to establish zirconium values that can be compared against those found by analytical procedures. Due to the inherent characteristics of the casting system and the U-Zr alloy, an offset between the calculated and measured zirconium content was recognized including its dependency on the mass of the uranium products. Given the random and systematic errors outlined, a reasonable fit of calculated to measured zirconium values has been presented.

\section{Acknowledgements}

The authors would like to acknowledge the Fuel Conditioning Facility operations personnel for their recent contributions and the Analytical Laboratory staff for chemical services. This work

was supported by the U.S. Department of Energy, Office of Nuclear Energy, Science, and Technology, under DOE-NE Idaho Operations Office Contract DE-AC07-05ID14517.

\section{References}

[1] C.E. Till, Y.I. Chang, Plentiful Energy - The Story of the Integral Fast Reactor, CreateSpace, Charleston, SC (2012).

[2] H.F. Jelinek, G.M. Iverson, Nuc. Sci. Eng. 12 (1962) 405.

[3] B.R. Westphal, R.D. Mariani, JOM 52, 9 (2000) 21-25.

[4] B.R. Westphal, K.C. Marsden, D. Vaden, J.C. Price, M.F. Simpson, in: Proc. Pu FuturesThe Science 2010, American Nuclear Society, Keystone, CO (2010) 352-3.

[5] H. Fredricksson, Interpretation and Use of Cooling Curves (Thermal Analysis), in: J.R. Davis (ed.), ASM Handbook, vol. 15, American Society for Metals, Metals Park, OH (1992) 182. 
[6] S.X. Li, D. Vaden, B.R. Westphal, G.L. Fredrickson, R.W. Benedict, T.A. Johnson, Nuc. Tech. 166, 2 (2009) 180.

[7] T.C. Totemeier, R.D. Mariani, J. Nucl. Mat. 250 (1997) 131.

[8] C.E. Stevenson, The EBR-II Fuel Cycle Story, American Nuclear Society, LaGrange, IL (1987).

[9] L. Backerud, B. Chalmers, Trans. Met. Soc. AIME. 245 (1969) 309.

[10] N. Chvorinov, Giessserei 27 (1940) 201.

[11] D. Summers-Smith, J. Inst. Met. 83 (1954) 277.

[12] L. Leibowitz, R.A. Blomquist, A.D. Pelton, J. Nucl. Mat. 167 (1989) 76.

[13] A. Maeda, Y. Suzuki, T. Ohmichi, J. Alloy Comp. 179 (1992) L21.

[14] M. Kurata, T. Ogata, K. Nakamura, T. Ogawa, J. Alloy Comp. 271-273 (1998) 636.

[15] W. Xiong, W. Xei, C. Shen, D. Morgan, J. Nucl. Mat. 443 (2013) 331.

[16] M.E. Kassner, D.E. Peterson, Phase Diagrams of Binary Actinide Alloys, ASM International, Materials Park, OH (1995) 247. 


\section{Figures}

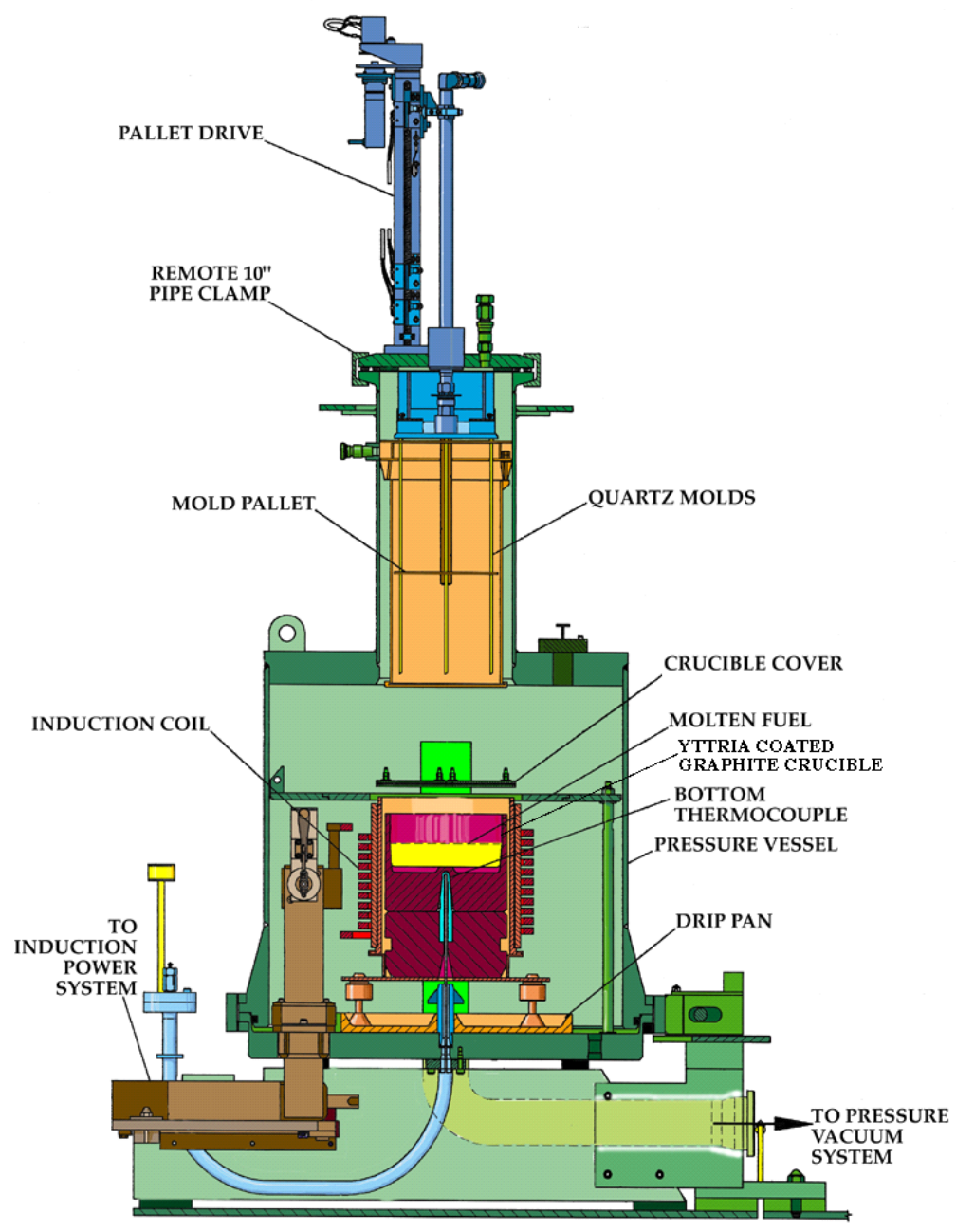

Figure 1. Schematic of casting furnace 


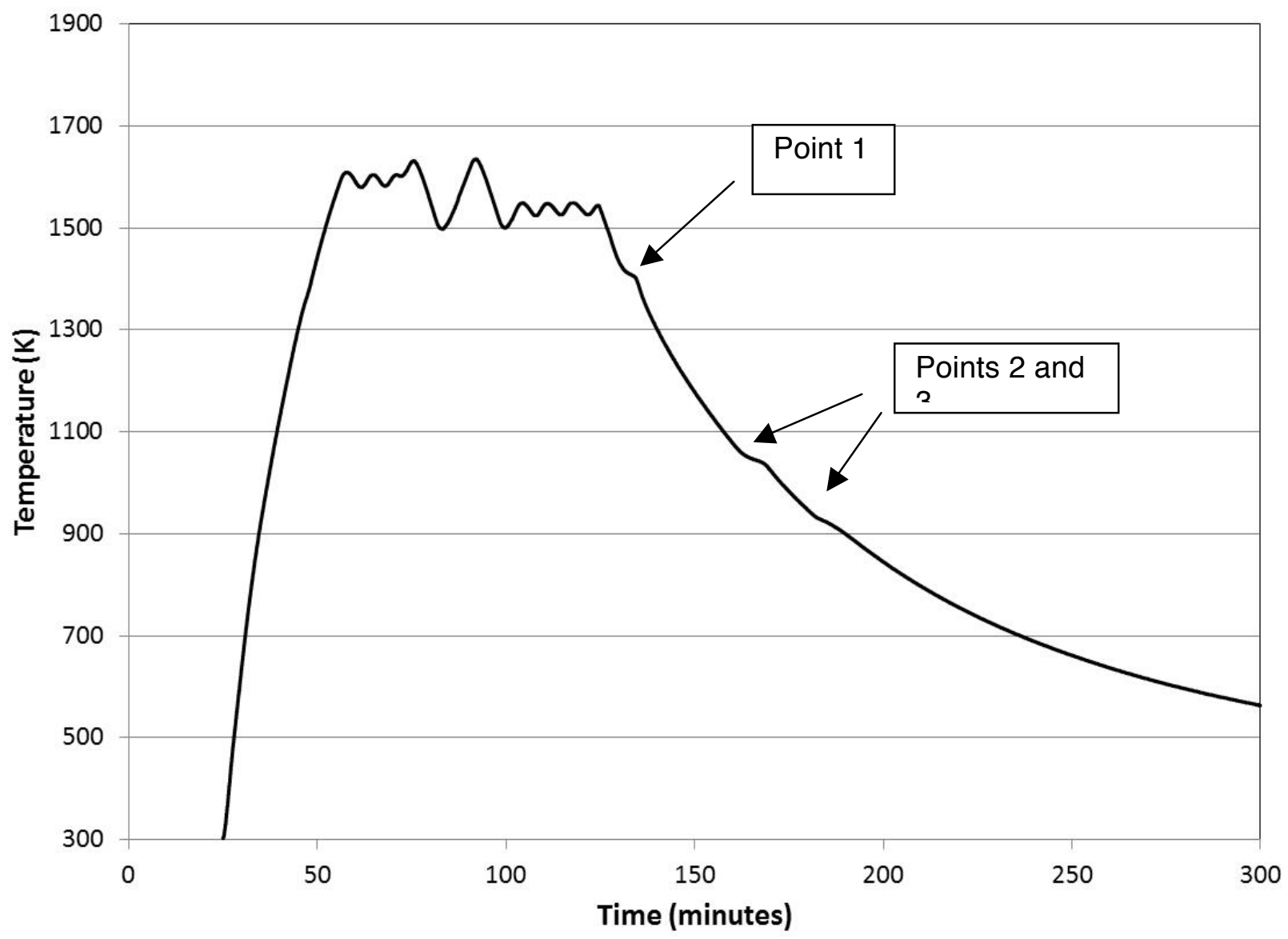

Figure 2. Typical heating and cooling curve for uranium product casting operations 


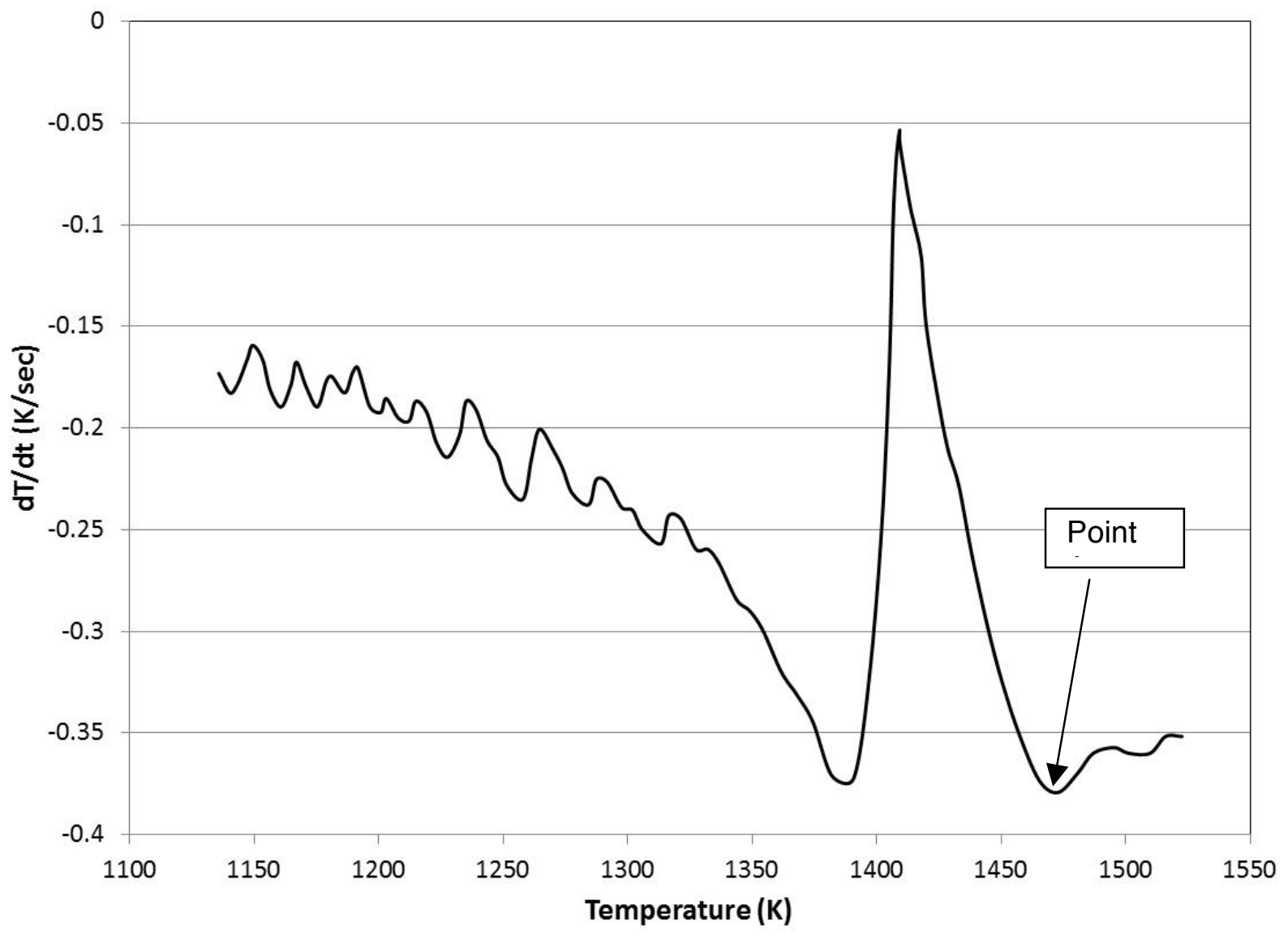

Figure 3. Typical first derivative analyses of cooling curve data 


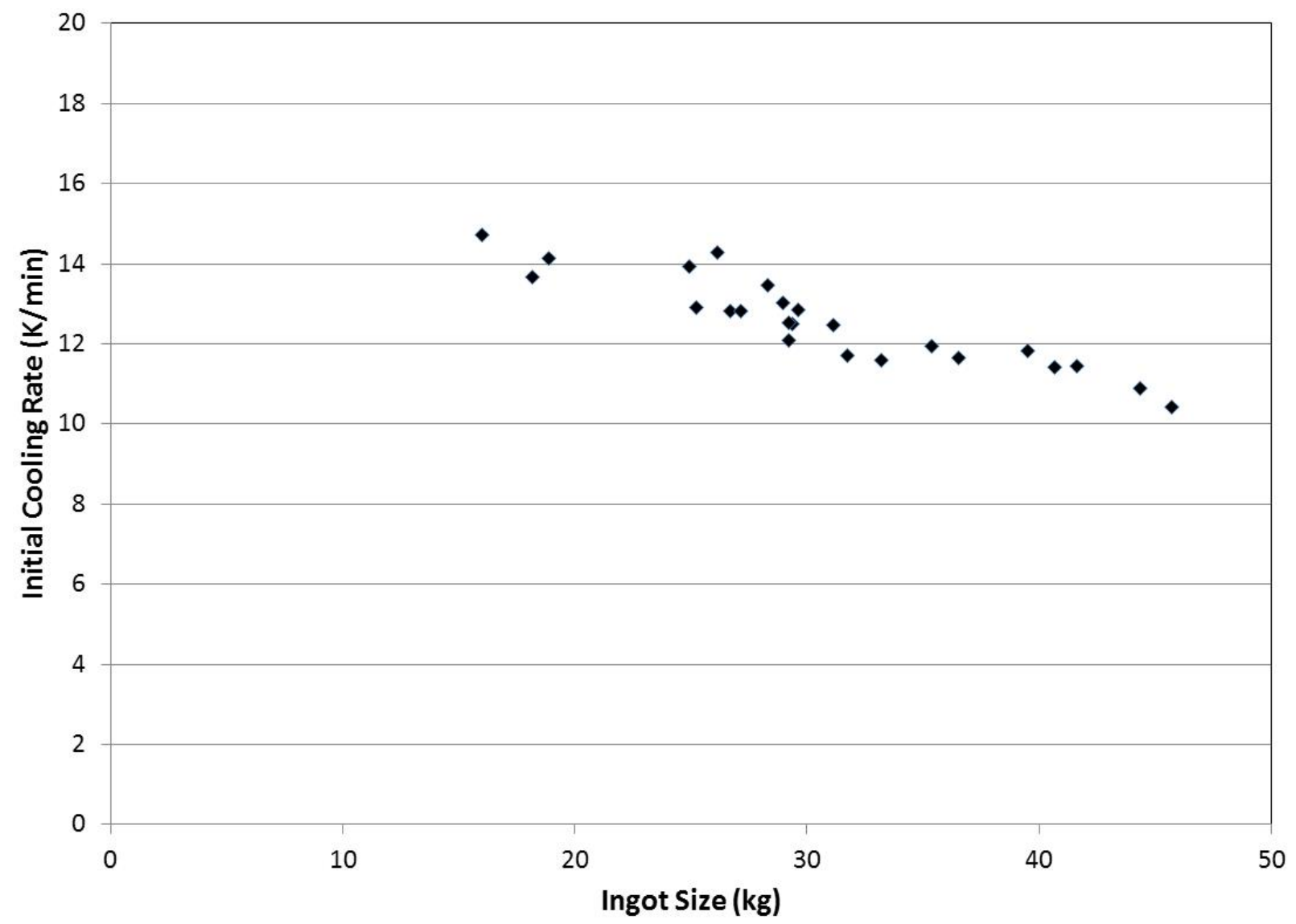

Figure 4. Effect of ingot size on initial cooling rate of uranium products 


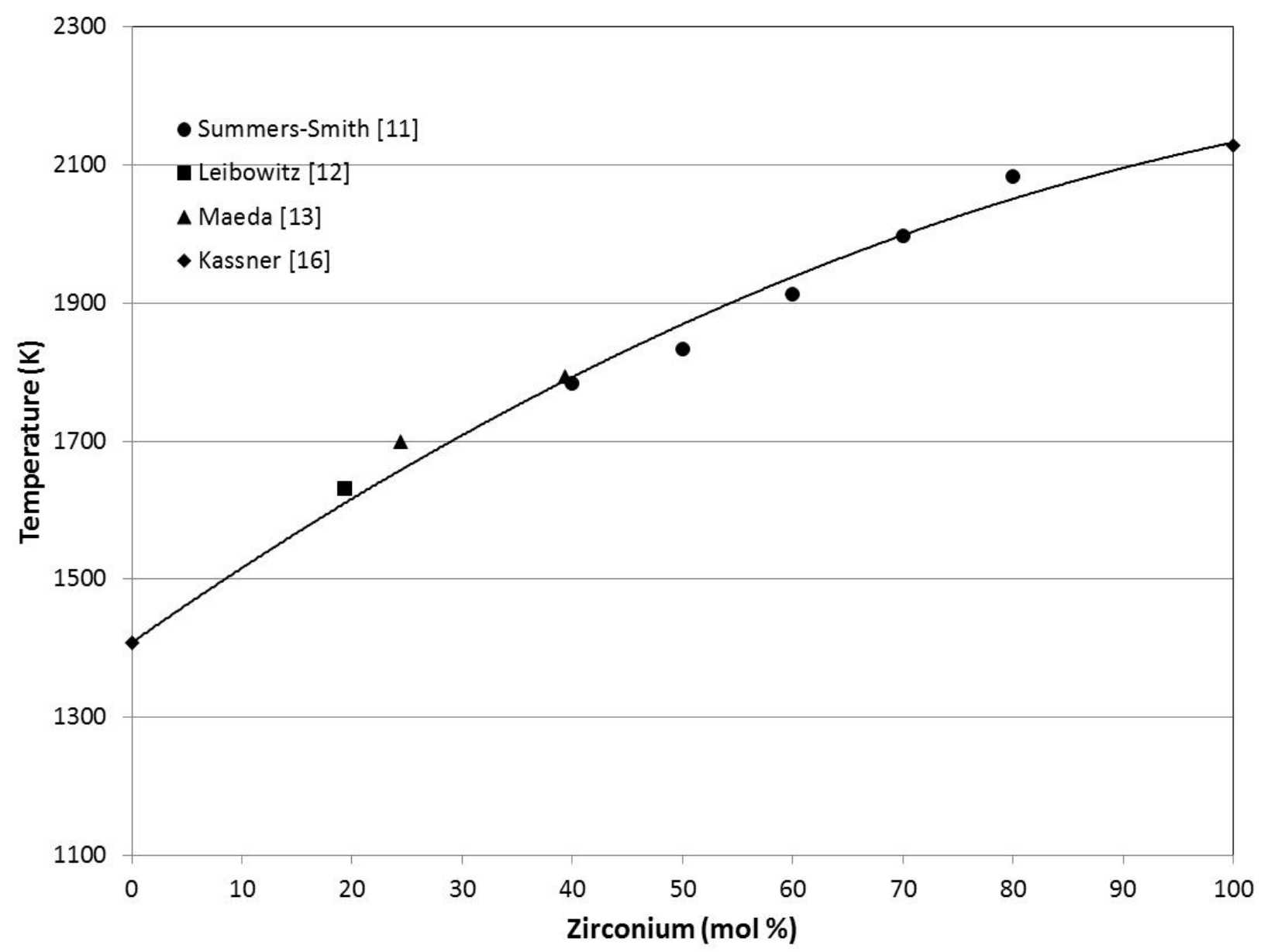

Figure 5. Liquidus portion of the U-Zr phase diagram based on experimental data, the solid line is a best fit of the data and is represented by equation (2) 
Table

Table 1. Comparison of zirconium concentrations ( $\mathrm{mol} \%$ ) from cooling curve and chemical analyses

\begin{tabular}{|c|c|c|c|c|c|}
\hline $\begin{array}{l}\text { Uranium } \\
\text { Product }\end{array}$ & $\begin{array}{c}\text { Mass } \\
(\mathrm{kg})\end{array}$ & $\begin{array}{c}\text { Liquidus } \\
\text { Temperature } \\
\text { from CCA } \\
(\mathrm{K})\end{array}$ & $\begin{array}{c}\text { Calculated } \\
\text { Zr } \\
(\mathrm{mol} \%)\end{array}$ & $\begin{array}{c}\text { Measured } \\
\mathrm{Zr} \\
(\mathrm{mol} \%) \\
\end{array}$ & $\begin{array}{c}\Delta \mathrm{Zr} \\
(\mathrm{mol} \%)\end{array}$ \\
\hline 1 & 18.9 & 1538 & 12.12 & 4.23 & 7.88 \\
\hline 2 & 16.0 & 1491 & 7.61 & 1.17 & 6.44 \\
\hline 3 & 39.5 & 1484 & 6.95 & 4.34 & 2.61 \\
\hline 4 & 25.2 & 1520 & 10.37 & 4.86 & 5.51 \\
\hline 5 & 29.4 & 1507 & 9.13 & 3.04 & 6.09 \\
\hline 6 & 29.2 & 1500 & 8.46 & 2.47 & 5.99 \\
\hline 7 & 44.3 & 1487 & 7.23 & 2.38 & 4.85 \\
\hline 8 & 33.2 & 1518 & 10.18 & 5.40 & 4.78 \\
\hline 9 & 41.6 & 1460 & 4.72 & 0.92 & 3.80 \\
\hline 10 & 36.5 & 1492 & 7.70 & 2.89 & 4.82 \\
\hline 11 & 31.1 & 1497 & 8.18 & 3.60 & 4.58 \\
\hline 12 & 40.7 & 1464 & 5.09 & 1.23 & 3.85 \\
\hline 13 & 29.2 & 1542 & 12.51 & 6.09 & 6.42 \\
\hline 14 & 31.7 & 1502 & 8.65 & 2.21 & 6.44 \\
\hline 15 & 29.0 & 1576 & 15.88 & 11.02 & 4.86 \\
\hline 16 & 26.7 & 1517 & 10.08 & 5.41 & 4.67 \\
\hline 17 & 27.1 & 1559 & 14.18 & 6.85 & 7.33 \\
\hline 18 & 26.2 & 1571 & 15.38 & 7.97 & 7.41 \\
\hline 19 & 29.6 & 1468 & 5.46 & 0.12 & 5.34 \\
\hline 20 & 24.9 & 1516 & 9.99 & 2.08 & 7.90 \\
\hline
\end{tabular}




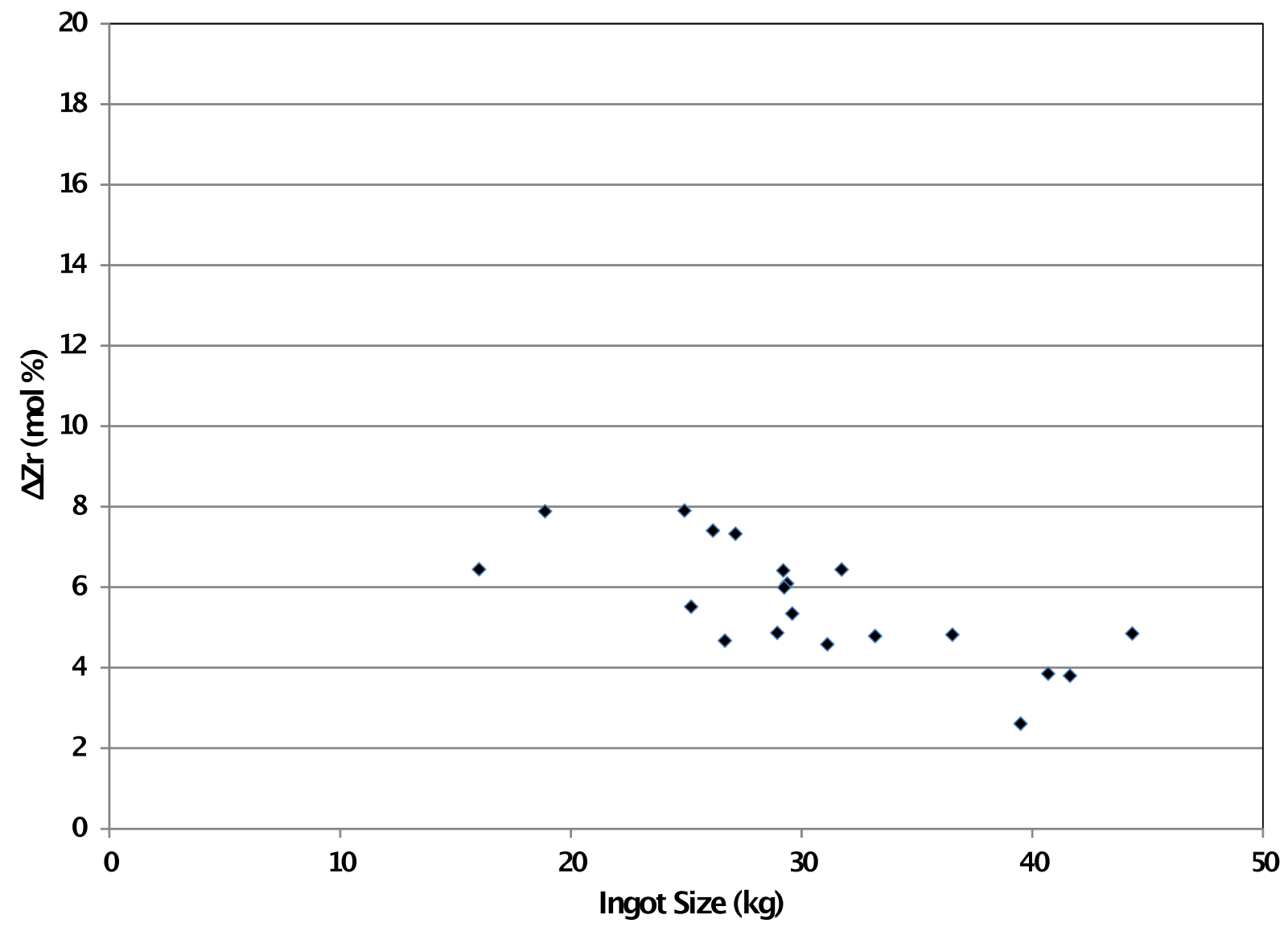

Figure 6. Effect of ingot size on $\Delta \mathrm{Zr}$ (mol \%) for uranium products 


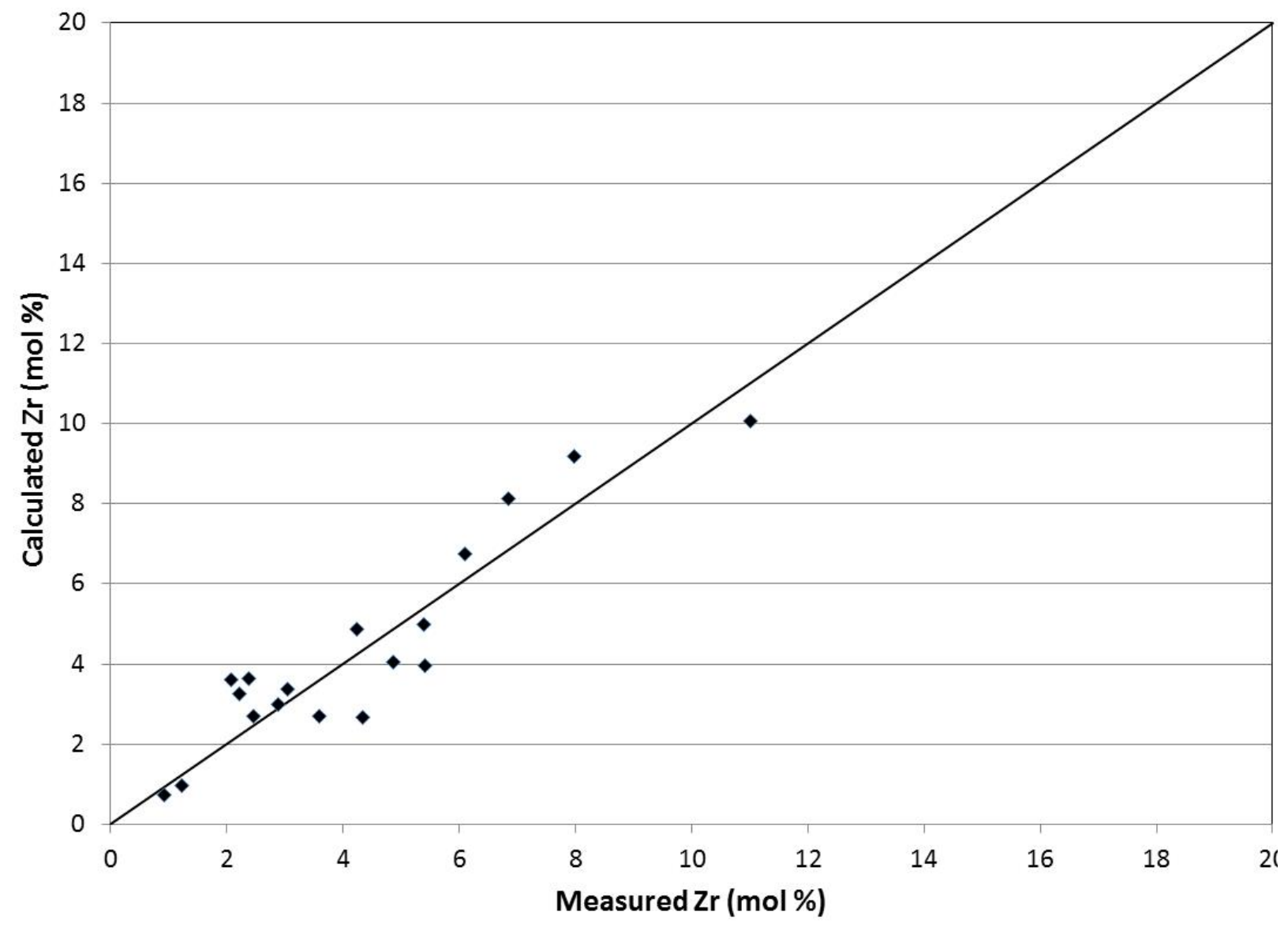

Figure 7. Comparison of measured to calculated Zr contents for uranium products 